\title{
Produção e comercialização do guaco (Mikania laevigata Schultz Bip. ex Baker) na região Sul do Estado do Paraná
}

MATSUSHITA, M.S. ${ }^{*}$; CORRÊA JÚNIOR, C. ${ }^{1 ;}$ SANTOS, A.J. ${ }^{2}$; HOSOKAWA, R.T. ${ }^{2}$

IInstituto Emater, Rua da Bandeira, 500, Curitiba, PR, CEP80.035-270, matsushita@emater.pr.gov.br, plamed@ emater.pr.gov.br 2Universidade Federal do Paraná, Rua dos Funcionários, 1540, Curitiba, PR, CEP 80.035-050, ajsantos@ufpr.br, rth@japan.org.br *Autor para correspondência: matsushita@emater.pr.gov.br

\begin{abstract}
RESUMO: O Estado do Paraná destaca-se pela tradição no cultivo de plantas medicinais. $O$ aumento em sua demanda através da busca de culturas alternativas e rentáveis e o estímulo a uma agricultura ecologicamente sustentável fomentou os agricultores a diversificarem a produção. A pesquisa de campo nos diferentes elos da cadeia produtiva do guaco permitiu construir seu fluxograma, caracterizar o sistema e fluxo de produção, os seus custos e receitas para analisar as Margens e Markups de comercialização. Os sistemas de coleta com enriquecimento e de cultivo apresentaram resultados diferenciados em relação ao seu custo de produção, onde o produtor/coletor alcança uma rentabilidade de 48,9\%, menor margem de comercialização entre todos os elos da cadeia, enquanto o produtor que cultiva o guaco como exploração obtém uma margem de comercialização de $346,4 \%$. As maiores margens de comercialização $(1.733,3 \%)$ estão nos elos fora da porteira das propriedades, percentual entre diferença de preço pago pelo consumidor e o preço recebido pelo produtor/coletor. Os produtores/coletores podem agregar mais renda em vários elos da cadeia produtiva através da organização dos produtores e a melhoria no processo produtivo, possibilitando a melhoria econômica e social nas propriedades familiares, reduzindo o impacto ambiental e garantindo a sustentabilidade dos sistemas de produção.
\end{abstract}

Palavras-chave: Plantas medicinais, Guaco, Mikania laevigata Schultz, comercialização.

\begin{abstract}
Production and commercialization of guaco (Mikania laevigata Schultz Bip. ex Baker) in the south of Paraná State. The State of Parana stands out for its tradition in the medicinal plants cultivation. The increase of the demand due to the search of alternative and profitable crops and the impulse to an environmentally sustainable agriculture encouraged farmers to diversify production. The field research about the different links of the guaco supply chain allowed the construction of its flowchart, the characterization of the production system and flow, as well as the knowledge of its costs and revenues in order to analyze the commercialization margins and markups. The collection systems with enrichment and the cultivation ones presented different results in relation to its production cost, with the producer/ collector reaching a yield of $48.9 \%$, the lowest commercialization margin among all links of the chain, while the farmer who cultivates guaco gets a commercialization margin of $346.4 \%$. The largest commercialization margins $(1,733.3 \%)$ are in the links outside the properties' gates, as the percentage difference between the price paid by the consumer and the one received by the producer/collector. Producers/collectors can add more income in several links of the supply chain through the producers' organization and by improvements in the production process, enabling the economic and social enhancement at the family farms, thus reducing the environmental impact and ensuring the sustainability of production systems.
\end{abstract}

Keywords: Medicinal plant, Guaco, Mikania laevigata Schultz, commercialization.

\section{INTRODUÇÃO}

A sustentabilidade das atividades agropecuárias está diretamente relacionada com os impactos ambientais, econômicos e sociais provocados pelo uso e ocupação do solo e pelas suas práticas de manejo. Atualmente nota-se uma crescente preocupação global em relação às questões ambientais, saúde pública, produção e geração de alimentos e distribuição de rendas no 
mundo. Portanto, o equilíbrio entre o crescimento econômico e a preservação ambiental deve ser uma busca permanente.

Motta (1998) e Brown (2003) fazem referência sobre as ações onde os seres humanos causaram alterações sem precedentes nos ecossistemas, nas últimas décadas, para atender às crescentes demandas por alimentos, água, fibras e energia. As tecnologias e conhecimentos disponíveis podem reduzir consideravelmente o impacto humano nos ecossistemas, porém a participação das comunidades (locais, regionais ou globais) que compartilham dos benefícios aumenta as chances de sucesso na preservação e recuperação dos recursos naturais.

Segundo Alexiades \& Shanley (2004), Carvalho (2006) e Alonso (2008), a Organização Mundial da Saúde estima que $80 \%$ das pessoas dos países em desenvolvimento, no mundo, dependem da medicina tradicional para suas necessidades básicas de saúde e que cerca de $85 \%$ da medicina tradicional envolve o uso de extratos de plantas.

O Plano Nacional das Cadeias de Produtos da Sociobiodiversidade contempla a medicina tradicional e o uso de plantas medicinais como componentes da estratégia para o desenvolvimento sustentável das comunidades locais. Levando-se em consideração a participação das comunidades (locais, regionais ou globais) preconizada por Motta (1998) e Brown (2003), o Ministério do Desenvolvimento Agrário - MDA, Ministério do Meio Ambiente - MMA e Ministério do Desenvolvimento Social e Combate a Fome - MDS elaboraram em 2009 o Plano Nacional de Promoção das Cadeias de Produtos da Sociobiodiversidade, como parte da estratégia do governo federal de articular as políticas de governo voltadas à promoção do desenvolvimento sustentável, geração de renda e justiça social (Brasil, 2009).

Brasil (2006) destaca a importância mundial da medicina tradicional recomendada pela Organização Mundial da Saúde (OMS) na prestação de assistência social, especialmente às populações que têm pouco acesso aos sistemas de saúde, e solicitou aos estados-membros que intensificassem a cooperação entre praticantes da medicina tradicional, com emprego de remédios tradicionais de eficácia científica demonstrada, a fim de reduzir os gastos com medicamentos.

Lorenzi (2008) relata que o Brasil possui a flora arbórea mais diversificada do mundo, e que a necessidade de produzirmos riquezas infinitamente deve estar alicerçada em um desenvolvimento auto-sustentado, considerando a relação da vida do homem com o meio ambiente. $O$ autor ainda cita que não é preciso domar a natureza, mas sim aprender com ela, onde os bosques heterogêneos de essências nativas formam um ecossistema em equilíbrio.

Vieira et al. (2002) destacam o Brasil entre os países de maior biodiversidade mundial, abrigando cerca de 50 mil espécies de plantas superiores, distribuídas nos grandes biomas: Amazônia (25-30 mil espécies), Mata Atlântica (16 mil espécies), Cerrado (7 mil espécies) e demais espécies distribuídas na Caatinga e Floresta Subtropical. Além da diversidade de recursos genéticos, o Brasil possui uma diversidade de etnias, com forte influência em nosso hábito alimentar e cultural, em especial, no que diz respeito ao uso de plantas medicinais e aromáticas, onde a maioria das espécies nativas necessita de estudos básicos, além de seu cultivo ainda ser incipiente ou inexistente.

Ming (2002), no relato dos resultados na $1^{\text {a }}$ Reunião Técnica de Trabalho sobre Estratégias para Conservação e Manejo de Recursos Genéticos de Plantas Medicinais e Aromáticas, considerou - Guaco (Mikania glomerata Spreng; Mikania hirsutissima DC.; Mikania laevigata Schultz Bip. Ex Baker), dentre as 24 espécies com prioridade alta no bioma Mata Atlântica para pesquisa sobre sistema reprodutivo, biologia floral, diversidade genética, dinâmica de populações e cadeia produtiva.

Segundo Corrêa Júnior \& Scheffer (2004), o Estado do Paraná destaca-se pela maior tradição no cultivo de plantas medicinais, que iniciou há mais de 100 anos com o cultivo de camomila como cultura alternativa de inverno na Região Metropolitana de Curitiba - RMC, que logo se tornou referência para esta espécie no Brasil. Em 1994, o Estado do Paraná já era fornecedora de $90 \%$ da demanda nacional de plantas medicinais cultivadas. Nesta época vários laboratórios da região e do estado intensificaram a fabricação de produtos à base de plantas medicinais, aromáticas e condimentares, aumentando a demanda regional por estas culturas por empresas como Nutrimental, Boticário, Herbarium, Leão Júnior, KrisBelt, entre outras.

O aumento na demanda de plantas medicinais, a busca de culturas alternativas e rentáveis por parte dos agricultores, o estímulo a uma agricultura ecologicamente sustentável por parte da então Empresa de Assistência Técnica e Extensão Rural do Paraná (EMATER-PR), hoje Instituto Paranaense de Assistência Técnica e Extensão Rural (Instituto EMATER), fomentaram as iniciativas dos agricultores que logo diversificaram a produção e passaram a cultivar, além da camomila, outras espécies exóticas (hortelã, campim limão, calêndula, dentre outras) e, mais recentemente, também nativas (espinheira santa, marcela, dentre outras) (Corrêa Júnior \& Scheffer, 2004).

Segundo Brasil (2010), o Sistema Único de Saúde (SUS) utiliza medicamentos fitoterápicos

Rev. Bras. PI. Med., Campinas, v.17, n.3, p.351-359, 2015. 
aprovados pela Agência Nacional de Vigilância Sanitária (ANVISA) e, por isso, são considerados seguros e eficazes para a população. Desde 2008, o SUS fornece para 13 unidades federativas (RN, PB, SE, BA, TO, MT, DF, GO, RJ, PR, SC, RO e RS) medicamentos fitoterápicos feitos à base de espinheira santa (Maytenus ilicifolia) para gastrites e úlceras e guaco (Mikania glomerata) para tosses e gripes, em diversas apresentações, financiados com recursos da União, Estados e Municípios.

Apesar de oficialmente registrada na farmacopéia, Oliveira et al. (1986; 1994) observaram que os produtos comercializados não eram compostos somente de folhas de Mikania glomerata, mas também de outras partes aéreas como caules e até as inflorescências. Além disso, eram comercializadas outras espécies, entre as quais a Mikania laevigata era a mais presente. Os ervanários baseavam-se na morfologia externa para reconhecer as plantas. Isto levou a erros, pois as duas espécies têm a morfologia externa e interna assemelhadas. As substâncias químicas majoritárias isoladas das duas espécies são similares. Então, concluíram que a M. laevigata é a sucedânea do guaco oficial.

As referencias indicam a incidência de guaco nos fragmentos florestais da região de ocorrência da Floresta Ombrófila Mista. O seu uso popular e comercial amplia o seu potencial de mercado como medicinal, sendo estratégico para a conservação dos recursos naturais, sociais e culturais para a comunidade.

Autores consultados, como Carollo (2008); Corrêa Júnior et al. (1994, 2006); Kolbes (2007); Lorenzi (2002); Martins et al. (2000); Ramos (2008); Teske \& Trentini (1994); Velloso \& Peglow (2003) descrevem o uso do guaco como planta melífera, produtora de óleo essencial e com os seguintes usos na medicina popular: amargo, antigripal, anti-inflamatório, antinevrálgico, antirreumático, antisséptico, béquico, broncodilatador, calmante, cicatrizante, depurativa, diurética, emoliente, expectorante, febrífugo, fluidificante, peitoral, sudorífico, tônico, vulnerário e ação antiofídica e inibidor do crescimento bacteriano.

Segundo Lorenzi (2002), a espécie Mikania glomerata Spreng pertence a família Asteraceae, conhecida pelo nome popular de guaco, guacode-cheiro, guaco-liso, guaco-trepador, uaco, cipóalmecega-cabeludo, cipó-catinga, cipó-sucuriju, coração-de-jesus, erva-cobre, erva-das-serpentes, erva-de-cobra, erva-de-sapo e erva-dutra. É uma planta nativa do sul do Brasil, trepadeira sublenhosa, de grande porte e perene, usada há séculos na medicina popular. As suas folhas possuem ação tônica, depuratica, febrífuga e peitoral, estimulante do apetite e antigripal. As informações etnofarmacológica citam o uso em inflamações na boca e na garganta, traumatismo, nevralgias, prurido e dores reumáticas. Dessas propriedades somente a ação sobre as vias respiratórias, justificadas pelo seu efeito broncodilatador, antitussígeno, expectorante e antiedematogênico foi confirmada em estudos científicos e indicadas nos programas de fitoterapia em saúde pública.

A avaliação econômica e margens relativas estão relacionadas aos seus custos de produção e margens de comercialização em seus diferentes elos de comercialização. Para a Companhia Nacional de Abastecimento - CONAB (2010), o custo de produção agrícola é uma excepcional ferramenta de controle e gerenciamento das atividades produtivas e de geração de importantes informações para subsidiar a tomada de decisão pelos produtores rurais e formulação de estratégias pelo setor público.

Segundo Corrêa Júnior et al. (2011), os sistemas de coleta em fragmentos florestais enriquecidos com o guaco e o sistema cultivado em espaldeira apresentam características, custos, produção, qualidade e preço diferenciados.

Segundo Mendes (1998), uma maneira de avaliar os ganhos nos diferentes níveis de comercialização é através do cálculo dos índices de Margem e "Markups" de Comercialização. A margem bruta de comercialização refere-se ao valor percentual de participação de cada um dos níveis de comercialização na formação do preço final do produto. A margem total $(\mathrm{Mt})$ refere-se à diferença do preço pago pelo consumidor e o preço pago ao produtor. Algebricamente Mt pode ser também calculada pela somatória de todas as margens dos níveis de comercialização.

Em termos absolutos o Markup (Mk) corresponde à margem de comercialização, a qual refere-se a diferença de preços em diferentes níveis do sistema de comercialização. Em termos relativos, o Markup mostra o percentual de aumento entre os preços de venda e de compra relativamente ao preço de compra, ou, entre o preço de venda e o custo de produção relativa ao custo de produção (Mendes, 2004).

A proposta deste trabalho é identificar a ocorrência e o uso popular do guaco na microbacia Rio Verde, caracterizar o sistema de produção, o fluxo do produto na cadeia produtiva, os seus custos e receitas e analisar o markup de comercialização, comparando os sistemas de guaco coletado no fragmento florestal e cultivado como exploração semi-perene.

\section{MATERIAL E MÉTODO Caracterização da área}

A pesquisa foi desenvolvida em um fragmento florestal em estágio médio de sucessão 
localizada na microbacia hidrográfica Rio Verde, nos municípios de Campo Largo, Campo Magro, Balsa Nova e Araucária, PR (Figura 1), entre a latitude $25^{\circ} 25^{\prime} 20^{\prime \prime}$ Sul e longitude $49^{\circ} 27^{\prime} 23^{\prime \prime}$ Oeste com uma altitude entre 920 e $960 \mathrm{~m}$ acima do nível do mar. O fragmento está em uma área de distribuição natural da Floresta Ombrófila Mista (FOM), com significativos remanescentes neste estágio, importantes pela ocorrência natural e exploração de produtos da sociobiodiversidade florestal (plantas medicinais, aromáticas, ornamentais e artesanais) utilizados pelas comunidades locais e também comercializados por diversas empresas do setor. O clima da região é do tipo $\mathrm{Cfb}$, de acordo com a classificação de Köppen, apresentando estações climáticas bem definidas, com chuvas distribuídas durante todo o ano, com inverno rigoroso e geadas severas e com umidade relativa do ar entre 80 a $85 \%$. A precipitação média anual fica entre 1.400 e $1.600 \mathrm{~mm}$. A temperatura média anual é de aproximadamente $16,5^{\circ} \mathrm{C}$, com mínimas podendo atingir valores negativos inferiores a $-5^{\circ} \mathrm{C}$ e máximas superiores a $33^{\circ} \mathrm{C}$ (IAPAR, 2000). O fragmento está localizado em relevo ondulado a forte ondulado, possuindo solo com textura argilosa, classificado como Cambissolo húmico alumínico (EMBRAPA, 1999).

De acordo com os dados apresentados por Corrêa Júnior \& Scheffer (2004), atualizado em 2008, o custo de produção de plantas medicinais, aromáticas e condimentares envolve os custos fixos e as despesas de custeio desde a implantação da cultura até o término da secagem e é determinado pela espécie que se vai cultivar e o sistema de cultivo (policultivo). Dessa forma o cultivo de plantas medicinais requer grande quantidade de mão de obra quando comparado com outras atividades e proporciona, em média, ocupação para uma pessoa por hectare. Além disso, há necessidade de mão de obra sazonal de até 10 pessoas por módulo ( 3 a 5 hectares).

Os dados primários utilizados neste trabalho foram coletados em pesquisa de campo junto aos técnicos da extensão rural, produtores rurais, mateiros e às empresas localizadas na região metropolitana de Curitiba e os dados secundários foram obtidas junto a instituições públicas e privadas, ligadas às atividades agroflorestais no estado, num total de 10 entrevistados. Os principais dados primários utilizados na pesquisa foram: tecnologia, qualidade dos produtos, custos de produção, quantidades extraídas, comercializadas e preços de mercado nos diferentes elos da cadeia.

Selecionou-se no fragmento florestal de 1,0 ha, enriquecido com 830 plantas de guaco, para a coleta dos dados. O Sistema de coleta com enriquecimento considerou o valor das mudas, serviços de coveamento, plantio e replantio para o enriquecimento do fragmento florestal. Os custos variáveis contemplam os serviços de colheita, transporte (massa verde), picagem, classificação, secagem e transporte (produto seco). Enquanto o custo fixo remunera o capital investido no empreendimento.

As informações do sistema cultivado com guaco foram obtidas através de acompanhamento, levantamento e coleta de dados técnicos e econômicos de todas as fases de produção. Os

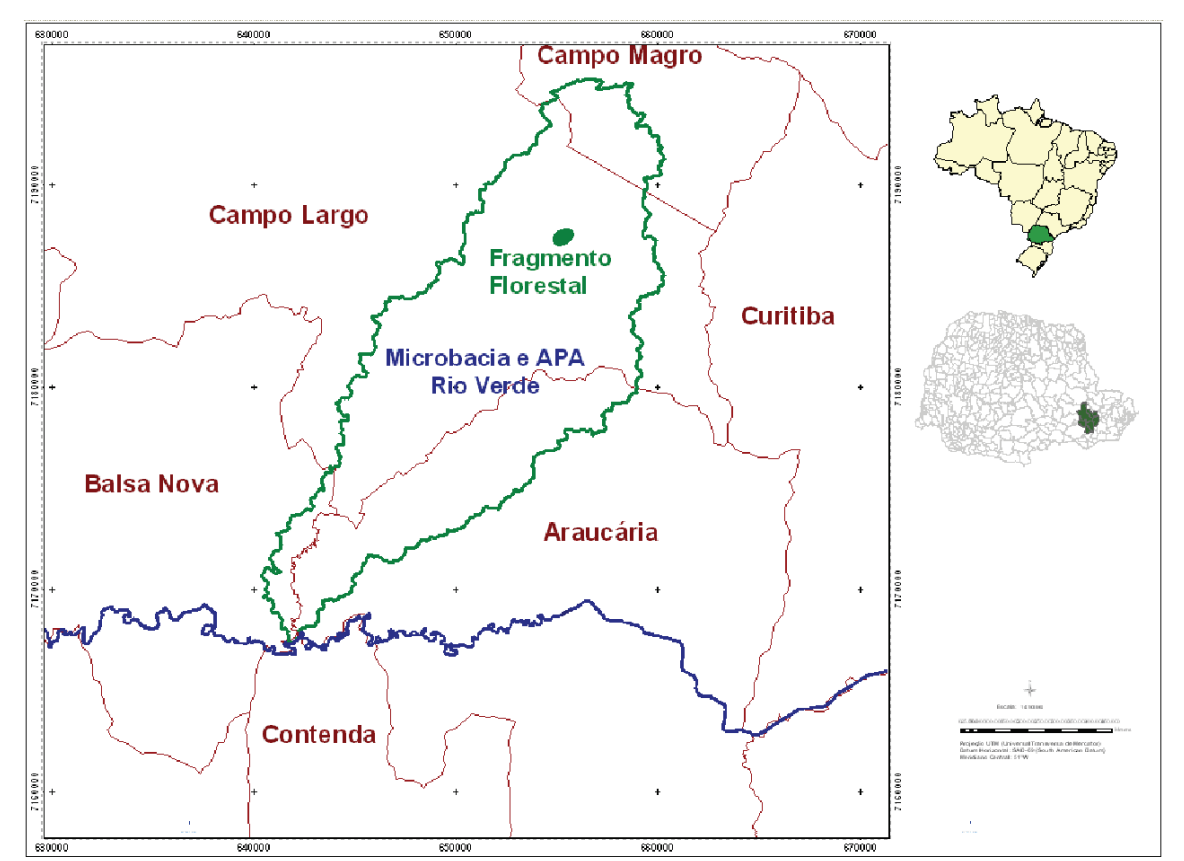

FIGURA 1. Localização da área de estudo, microbacia e APA Rio Verde, Campo Largo, PR (2011)

Rev. Bras. PI. Med., Campinas, v.17, n.3, p.351-359, 2015. 
custos de produção foram divididos em custos variáveis e fixos: os custos variáveis variam com a quantidade produzida e são consumidos totalmente durante o ciclo produtivo, enquanto os custos fixos são os custos da estrutura da propriedade envolvida com a produção. Para o sistema cultivado foram considerados os materiais, insumos e serviços para a implantação e manutenção da lavoura e da espaldeira, serviços de colheita, transporte (massa verde), picagem, classificação, secagem e transporte (produto seco), além dos custos com depreciações e remunerações do capital investido.

O produto destinado aos laboratórios recebe um beneficiamento denominado moagem, reduzindo as folhas picadas a pó, e seguem para outros beneficiamentos. Já o produto comercializado para chás é apenas picado, selecionado, seco e acondicionado em embalagens apropriadas.

A metodologia utilizada foi baseada em Corrêa Júnior (2011), e consistiu em:

- identificar os principais componentes da cadeia produtiva no sul do estado do Paraná;

- caracterizar o sistema de produção, o fluxo do produto na cadeia produtiva, os seus custos e receitas;
- construir seu fluxograma;

- analisar as Margens e Markups de comercialização;

- identificar os principais pontos positivos e negativos da atividade econômica

\section{RESULTADOS E DISCUSSÃO \\ Características da produção}

A cadeia produtiva do guaco na região sul do Paraná se inicia com a obtenção de ramos e folhas provenientes de coleta seletiva em fragmentos florestais enriquecidos com plantas de guaco, ou através de cultivo tutorado sobre estrutura de arame em áreas específicas para culturas semiperenes, conforme o fluxograma apresentado na figura 2.

O fluxograma da cadeia produtiva do guaco (figura 2) é bastante simplificado. Inicia-se na propriedade com a coleta ou colheita dos ramos e folhas, realizada pelo próprio produtor ou por um coletor que as repassa para um produtor. O produtor faz o processamento primário, repassando-as a outros compradores intermediários que comercializa com as indústrias (fitoterápicos, suplementos

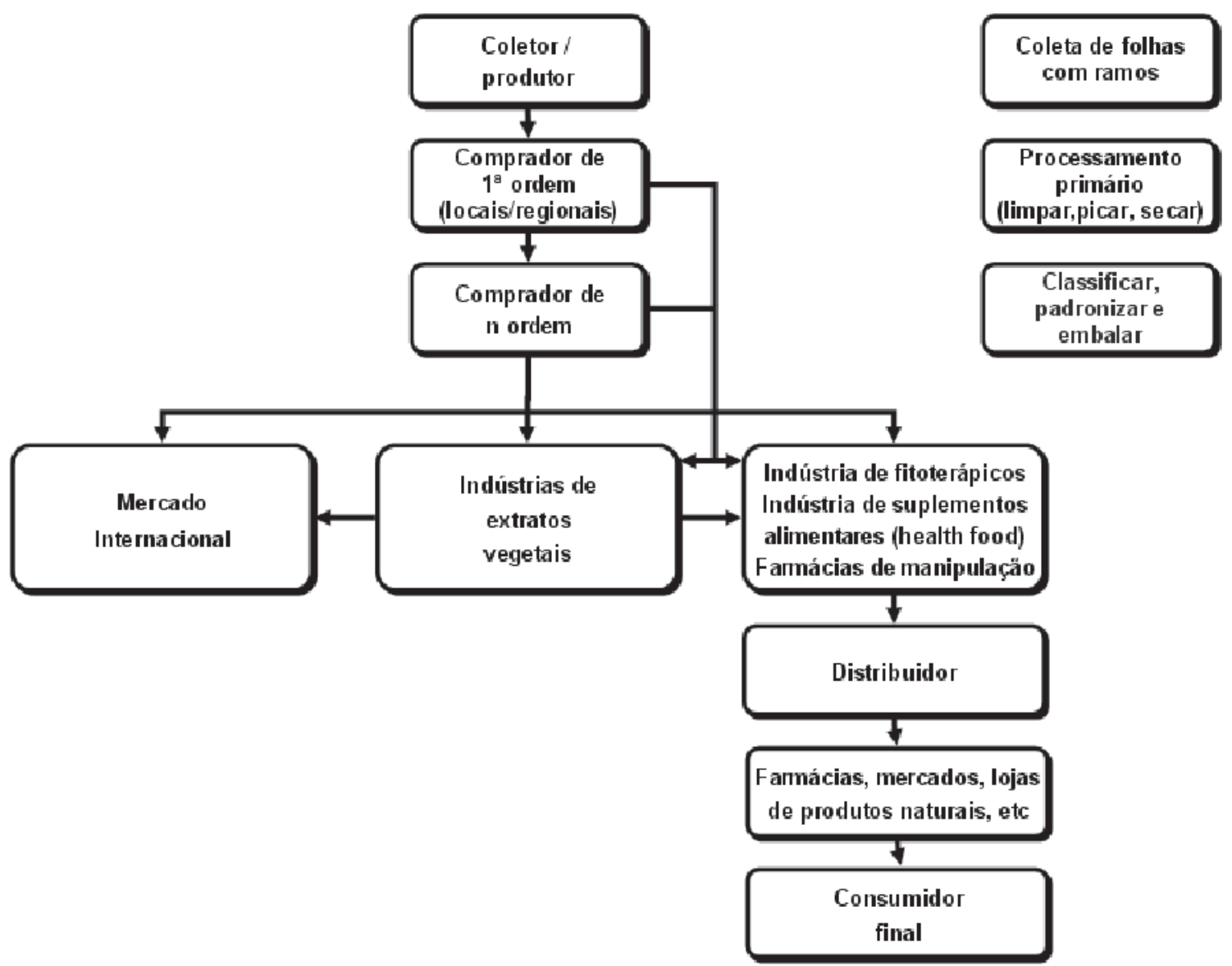

FIGURA 2. Fluxograma de produção e comercialização de Guaco (Mikania leavigata) Fonte: Matsushita \& Corrêa Júnior (2011). 
alimentares), farmácias de manipulação, indústrias de extratos vegetais e mercado internacional. As indústrias (fitoterápicos, suplementos alimentares) distribuem o produto através do comércio atacadista e varejista até o consumidor final.

Sistemas de coleta em fragmentos florestais enriquecidos: no fragmento florestal selecionado constatou-se uma produção anual de massa seca pronta para o comércio, conforme na tabela abaixo:

TABELA 1. Produção de guaco coletado em fragmento florestal

\begin{tabular}{cll}
\hline Ano & \multicolumn{2}{c}{ Produção (peso seco) } \\
\hline $1^{\circ}$ & $0,125 \mathrm{~kg} /$ planta & $100 \mathrm{~kg} / \mathrm{ha}$ \\
$2^{\circ}$ & $0,500 \mathrm{~kg} /$ planta & $400 \mathrm{~kg} / \mathrm{ha}$ \\
$3^{\circ}$ & $0,750 \mathrm{~kg} /$ planta & $600 \mathrm{~kg} / \mathrm{ha}$ \\
$4^{\circ}$ & $0,750 \mathrm{~kg} /$ planta & $600 \mathrm{~kg} / \mathrm{ha}$ \\
$5^{\circ}$ & $1,000 \mathrm{~kg} /$ planta & $800 \mathrm{~kg} / \mathrm{ha}$ \\
\hline
\end{tabular}

Fonte: Matsushita \& Corrêa Júnior (2011)

A produção em fragmentos florestais enriquecidos com o guaco iniciou com $125 \mathrm{~g}$ no $1^{\circ}$ ano, estabilizando a partir do $5^{\circ}$ ano com uma produtividade de $1.000 \mathrm{~g}$ por planta. Esta produtividade depende da fertilidade do solo e das condições climática (chuvas, temperatura). $\mathrm{O}$ fragmento florestal em estágio médio de sucessão permite boa luminosidade, desenvolvendo plantas com internódios curtos, aumentando o número de folhas e a sua produtividade.

$\mathrm{Na}$ tabela 2 o custo de implantação apresentou os seguintes resultados econômicos.

Este sistema pode ser adaptado para áreas de ocorrência natural do guaco, neste caso considerar a produtividade por plantas (tabela 1)
Sistema cultivado: o sistema cultivado considerou o guaco como uma exploração semiperene desenvolvido com tutoramento em espaldeira e apresenta anualmente uma produção de massa seca pronto para o comércio, conforme na tabela abaixo:

TABELA 3. Produção de guaco cultivado

\begin{tabular}{ccc}
\hline Ano & Produção (peso seco) & \\
\hline $1^{\circ}$ & $0,50 \mathrm{~kg} /$ planta & $1.650 \mathrm{~kg} / \mathrm{ha}$ \\
$2^{\circ}$ & $0,75 \mathrm{~kg} /$ planta & $2.475 \mathrm{~kg} / \mathrm{ha}$ \\
$3^{\circ}$ & $1,00 \mathrm{~kg} /$ planta & $3.300 \mathrm{~kg} / \mathrm{ha}$ \\
$4^{\circ}$ & $1,00 \mathrm{~kg} /$ planta & $3.300 \mathrm{~kg} / \mathrm{ha}$ \\
$5^{\circ}$ & $1,00 \mathrm{~kg} /$ planta & $3.300 \mathrm{~kg} / \mathrm{ha}$ \\
\hline
\end{tabular}

Fonte: Matsushita \& Corrêa Júnior (2011)

O sistema cultivado, com espaçamento de 3,0 x 1,0 m, considerou na implantação o valor dos insumos, serviços, materiais e montagem da espaldeira. Os custos variáveis contemplam os serviços de colheita, transporte (massa verde), picagem, classificação, secagem e transporte (produto seco). Enquanto o custo fixo remunera o capital investido no empreendimento e a depreciação das instalações.

A produção no sistema cultivado iniciou com $500 \mathrm{~g}$ no $1^{\circ}$ ano, estabilizando a partir do $3^{\circ}$ ano com uma produtividade de $1.000 \mathrm{~g}$ por planta. Esta produtividade depende da fertilidade do solo e das condições climática (chuvas, temperatura).

Os principais itens do custo de coleta de guaco referem-se ao uso da mão de obra que perfaz $88 \%$ do custo total. Como os agricultores familiares da região utilizam mão de obra familiar para coleta do guaco, estes valores são agregados à renda familiar, ampliando a margem bruta e o lucro.

TABELA 2. Análise econômica de guaco coletado em fragmento florestal

\begin{tabular}{|c|c|c|c|c|c|c|c|c|}
\hline Análise econômica: & Ano 0 & Ano 1 & Ano 2 & Ano 3 & Ano 4 & Ano 5 & Total & Média \\
\hline Implantação & 1.360 & & & & & & & \\
\hline Custos Variáveis $(\mathrm{R} \$)$ & & 710 & 1.615 & 2.120 & 2.120 & 2.550 & 9.115 & 1.823 \\
\hline Custos Fixos (R\$) & & 124 & 179 & 209 & 209 & 235 & 955 & 191 \\
\hline Custo Total $(\mathrm{R} \$)$ & & 834 & 1.794 & 2.329 & 2.329 & 2.785 & 10.070 & 2.014 \\
\hline Renda Bruta $(\mathrm{R} \$)$ & & 600 & 2.400 & 3.600 & 3.600 & 4.800 & 15.000 & 3.000 \\
\hline Margem Bruta (R\$) & & -110 & 785 & 1.480 & 1.480 & 2.250 & 5.885 & 1.177 \\
\hline Lucro $(\mathrm{R} \$)$ & & -234 & 607 & 1.271 & 1.271 & 2.015 & 4.930 & 986 \\
\hline Saldo anual $(R \$)$ & -1.360 & -234 & 607 & 1.271 & 1.271 & 2.015 & & \\
\hline Saldo anual acumulado (R\$) & -1.360 & -1.594 & -988 & 284 & 1.555 & 3.570 & & \\
\hline Valor presente $(\mathrm{R} \$)$ & -1.360 & -221 & 540 & 1.067 & 1.007 & 1.506 & & \\
\hline Valor presente acumulado $(\mathrm{R} \$)$ & -1.360 & -1.581 & -1.041 & 26 & 1.033 & 2.539 & & \\
\hline Valor Presente Líquido - VPL (R\$) & 2.539 & & & & & & & \\
\hline Taxa Interna de Retorno - TIR (\%) & 38,7 & & & & & & & \\
\hline
\end{tabular}

Fonte: Matsushita \& Corrêa Júnior (2011) 
TABELA 4. Análise econômica de guaco cultivado

\begin{tabular}{|c|c|c|c|c|c|c|c|c|}
\hline Análise econômica: & Ano 0 & Ano 1 & Ano 2 & Ano 3 & Ano 4 & Ano 5 & Total & Anual \\
\hline Implantação & 18.557 & & & & & & & \\
\hline Custos Variáveis $(\mathrm{R} \$)$ & & 7.142 & 8.697 & 10.772 & 10.602 & 10.602 & 47.815 & 9.563 \\
\hline Custos Fixos (R\$) & & 2.845 & 2.938 & 3.063 & 3.053 & 3.053 & 14.951 & 2.990 \\
\hline Custo Total (R\$) & & 9.987 & 11.635 & 13.835 & 13.655 & 13.655 & 62.766 & 12.553 \\
\hline Renda Bruta (R\$) & & 33.000 & 49.500 & 66.000 & 66.000 & 66.000 & 280.500 & 56.100 \\
\hline Margem Bruta (R\$) & & 25.858 & 40.803 & 55.228 & 55.398 & 55.398 & 232.685 & 46.537 \\
\hline Lucro $(\mathrm{R} \$)$ & & 23.013 & 37.865 & 52.165 & 52.345 & 52.345 & 217.734 & 43.547 \\
\hline Saldo anual (R\$) & -18.557 & 23.013 & 37.865 & 52.165 & 52.345 & 52.345 & & \\
\hline Saldo anual acumulado (R\$) & -18.557 & 4.456 & 42.321 & 94.486 & 146.832 & 199.177 & & \\
\hline Valor presente $(\mathrm{R} \$)$ & -18.557 & 21.710 & 33.700 & 43.799 & 41.463 & 39.116 & & \\
\hline Valor presente acumulado (R\$) & -18.557 & 3.153 & 36.853 & 80.652 & 122.114 & 161.230 & & \\
\hline Valor Presente Líquido - VPL (R\$) & 161.230 & & & & & & & \\
\hline Taxa Interna de Retorno - TIR (\%) & 163,3 & & & & & & & \\
\hline
\end{tabular}

Fonte: Matsushita \& Corrêa Júnior (2011)

O sistema de exploração do guaco cultivado apresenta um lucro bem superior ao sistema de coleta (44,2 vezes), porém necessita de um investimento 12,6 vezes superior, o que significa a necessidade de área específica para cultivo e maior capital para investimento inicial, representando maior risco ao produtor.

Os custos de produção e os preços de comercialização do guaco coletado e do cultivado apresentam diferencial devido à qualidade do produto, onde o coletado contém ramos e folhas de qualidade inferior, pois se desenvolve em ambiente sombreado no interior dos fragmentos florestais, enquanto o produto cultivado desenvolve-se em ambiente com controle dos fatores de produção.

Ao analisar a cadeia produtiva do guaco coletado no fragmento florestal e cultivado como exploração semi-perene, resultou em produto final para o consumidor o guaco seco embalado em pacotes de 30 gramas. O produtor/coletor obtém a menor margem de comercialização entre todos os elos da cadeia, recebendo $48,9 \%$ de rentabilidade sobre seus custos de produção, uma vez que possui um custo de produção de $\mathrm{R} \$ 4,03$ e comercializa por $R \$ 6,00$, representando $5,45 \%$ do preço final de venda. Enquanto a margem total de comercialização é de 1.733,3 \%, diferença entre o preço pago pelo consumidor $(\mathrm{R} \$ 3,30$ por pacote de $30 \mathrm{~g}$ ) e o preço recebido pelo produtor/ coletor ( $\mathrm{R} \$ 6,00$ por $\mathrm{kg}$ ). O produtor que cultiva o guaco como exploração, obtém uma margem de comercialização de 346,4 \%, considerando o seu custo de produção de $\mathrm{R} \$ 4,48$ e preço de comercialização de $\mathrm{R} \$ 20,00$ por kg.

O preço obtido pelo produtor que comercializa somente as folhas de guaco é 233,3 $\%$ superior ao preço obtido pelo produtor que comercializa o guaco misto (ramos e folhas). A separação e seleção das folhas de guaco reduzem o seu peso final em $67 \%$, resultando em $33 \%$ de folhas secas selecionadas para o comércio.

Segundo Matsushita (2010), as plantas medicinais existentes nos fragmentos florestais podem gerar receitas sem competição por terra, capital ou mão de obra com outras atividades da propriedade. O uso sustentável de produtos da sociobiodiversidade possibilita a melhoria econômica e social nas propriedades familiares através de sua exploração seletiva, incentivando a manutenção e ampliação dos fragmentos florestais, reduzindo o

TABELA 5. Preço e markup (Margem de comercialização) de comercialização do guaco coletado

\begin{tabular}{ccccccc}
\hline Elos da cadeia produtiva & $\begin{array}{c}\text { Preço de } \\
\text { venda pelo } \\
\text { produtor }\end{array}$ & $\begin{array}{c}\text { Preço de venda } \\
\text { pelo produtorl } \\
\text { compra-dor 1 } \\
\text { ordem }\end{array}$ & $\begin{array}{c}\text { Preço no } \\
\text { atacado / varejo } \\
\text { (granel) }\end{array}$ & $\begin{array}{c}\text { Preço no } \\
\text { atacado (pacote } \\
\text { de 30 g) }\end{array}$ & $\begin{array}{c}\text { Preço no varejo } \\
\text { - consumi-dor } \\
\text { (pacote de 30 g) }\end{array}$ & $\begin{array}{c}\text { Margem } \\
\text { total } \\
\text { (Mt) }\end{array}$ \\
Produto & Ramos e & Folhas a & Folhas selecio- & Folhas em & Folhas em \\
Guaco seco & folhas & granel & nadas a granel & pacotes de $30 \mathrm{~g}$ & pacotes de $30 \mathrm{~g}$ \\
Preço de venda $(\mathrm{R} \$ / \mathrm{Kg})$ & 6,00 & 20,00 & 30,00 & 60,00 & 110,00 \\
Markup - Margem de & $0,0 \%$ & $233,3 \%$ & $50,0 \%$ & $100,0 \%$ & $83,3 \%$ & $1.733,3 \%$ \\
comercialização $(\%)$ & & & & & & \\
\hline
\end{tabular}

Fonte: Matsushita \& Corrêa Júnior (2011)

Rev. Bras. PI. Med., Campinas, v.17, n.3, p.351-359, 2015. 
impacto ambiental e garantindo a sustentabilidade dos sistemas de produção.

\section{CONCLUSÕES}

A cadeia produtiva do guaco na região sul do Paraná é bastante simples, onde os agricultores familiares participam dos elos iniciais com a obtenção de ramos e folhas provenientes de coleta seletiva ou cultivo, desenvolvem o processamento primário através da limpeza, picagem, secagem e classificação do produto. O produtor/coletor obtém a menor margem de comercialização entre todos os elos da cadeia, recebendo 48,9\% de rentabilidade sobre seus custos de produção, enquanto a margem total de comercialização é de 1.733,3 \%, percentual entre diferença de preço pago pelo consumidor e o preço recebido pelo produtor/coletor. Os produtores que cultivam o guaco como exploração, obtém uma margem de comercialização de 346,4 \% sobre o seu custo de produção.

O guaco existente nos fragmentos florestais pode gerar receitas sem competição por terra, capital ou mão de obra com outras atividades agropecuárias, possibilitando a melhoria econômica e social nas propriedades familiares através de sua exploração seletiva, incentivando a manutenção e ampliação dos fragmentos florestais, reduzindo o impacto ambiental e garantindo a sustentabilidade dos sistemas de produção.

O sistema agroflorestal é uma alternativa para exploração do guaco, através de uma associação com espécies como a Espinheira-santa e outras espécies arbóreas. O cultivo do guaco como exploração apresenta uma boa rentabilidade, gerando trabalho para a população local, sendo que em uma área de 1 ha de cultivo, extrai-se em média 0,5 tonelada de folhas em uma única colheita anual, também se realiza uma outra colheita no inverno dependendo das condições edafoclimáticas.

Dentre as plantas medicinais, o guaco cultivado extensivamente em espaldeiras é que apresenta uma das maiores rentabilidades, com um lucro médio anual de $\mathrm{R} \$ 43.547,00$.

O guaco e a espinheira santa são as espécies prioritárias do Ministério da Saúde para o Programa Nacional de Fitoterápicos e Plantas Medicinais, por apresentarem eficácia medicinal comprovada através de estudos científicos e bom potencial de mercado. Porém, antes de cultivar em escala comercial recomenda-se realizar contratos com os compradores, para assegurar a comercialização de seu produto.

Os índices de Margens e Markups de comercialização demonstram que o varejista é o agente que recebe uma maior remuneração na cadeia produtiva desta matéria-prima, devido ao pagamento de baixos preços pelo produto, resultante da falta de informação, baixa qualidade do produto e o baixo nível de organização dos produtores. Assim sendo, a organização dos produtores e a melhoria no processo produtivo, agregaria renda aos agricultores em vários elos da cadeia produtiva.

O intercâmbio comercial e a agregação de valor na cadeia produtiva deve ser melhorada com a padronização da legislação de fitoterápicos do Brasil com a de outros países.

\section{REFERÊNCIAS}

ALEXIADES, M.N.; SHANLEY, P. Productos forestales, médios de subsistencia y conservacion. Estudios de caso sobre sistemas de manejo de productos forestales no maderables. Volumen 3 - America Latina. Jakarta, Indonésia: SMK Desa Putera, 2004.

ALONSO, J.R. Fitomedicina: curso para profissionais da área da saúde. São Paulo: Pharmabooks, 2008.

BRASIL. Ministério da Saúde. Política Nacional de Plantas Medicinais e Fitoterápicos. Brasília: Ministério da Saúde, 2006. 60 p.

BRASIL. Ministério do Desenvolvimento Agrário - MDA, Ministério do Meio Ambiente - MMA e Ministério do Desenvolvimento Social e Combate a Fome - MDS. Plano Nacional de promoção das cadeias de produtos da Sociobiodiversidade. Brasília: MDA, 2009.

BRASIL. Resolução do CONAMA n 425/2010, de 25 de maio de 2010. Dispõe sobre Critérios para a caracterização de atividades e empreendimentos agropecuários sustentáveis do agricultor familiar, empreendedor rural familiar, e dos povos e comunidades tradicionais como de interesse social para fins de produção, intervenção e recuperação de Áreas de Preservação Permanente e outras de uso limitado. Publicação DOU n 100. Brasília, DF: Diário Oficial da União, 2010. Disponível em: <http://www. mma.gov.br/port/conama/legiabre.cfm?codlegi=630. html>. Acesso em: 22 out. 2010.

BROWN, L. Eco-Economia. EPI - Earth Policy Institute / UMA - Universidade Livre da Mata Atlântica. 2003. Disponível em: <http://www. www.uma.org.br>. Acesso em: 10 out. 2010. 368p.

CARVALHO, P.E.R. Espécies Arbóreas Brasileiras, vol. 2. Brasília, DF: Embrapa Informação Tecnológica; Colombo, PR: Embrapa Florestas, 2006.

CAROLLO, C.A. Análise fitoquímica e avaliação dos efeitos dos tipos de adubação, da radiação solar e do estresse hídrico, no acúmulo de metabólicos secundários em espécies do gênero Mikania. 2008. 228p. Tese (Doutorado - Área de concentração em produtos naturais e sintéticos) - Faculdade de Ciências Farmacêuticas de Ribeirão Preto, Universidade de São Paulo, Ribeirão Preto.

CONAB - Companhia Nacional de Abastecimento. Custos de produção agrícola: a metodologia da Conab. Brasília: CONAB, 2010. 60 p.

CORREAA JUNIOR, C. et al. Cultivo de plantas medicinais, condimentares e aromáticas. 2 ed. Jaboticabal, SP: FUNEP, 1994.

CORRÊA JUNIOR, C. et al. Cultivo agroecológico de

Rev. Bras. PI. Med., Campinas, v.17, n.3, p.351-359, 2015. 
plantas medicinais, aromáticas e condimentares. Brasília: Ministério do Desenvolvimento Agrário, 2006. CORREAA JUNIOR, C. et al. O guaco (Mikania laevigata Schultz Bip. ex Baker): aspectos agronômicos e fitoquímicos. Curitiba: Emater, 2011. 36 p.

CORREAA JUNIOR, C.; SCHEFFER, M.C. Produção de plantas medicinais, condimentares e aromáticas no Estado do Paraná. In: Complexo agroindustrial das plantas medicinais, aromáticas e condimentares no Estado do Paraná - diagnóstico e perspectivas. Curitiba: Sociedade Paranaense de Plantas Medicinais: EMATER-PR: Embrapa Florestas, 2004, p. 48-68.

EMBRAPA. Centro Nacional de Pesquisa de Solos. Sistema brasileiro de classificação de solos. Brasília : EMBRAPA Produção de Informação, 1999.

IAPAR - Fundação Instituto Agronômico do Paraná. Cartas climáticas do Paraná. Londrina, 2000. CDROM. Versão 1.0. 2000.

KOLBES. C.V. Plantas medicinais. 63 ed. Francisco Beltrão, PR: ASSESSOAR, 2007.

LORENZI, H. Plantas medicinais no Brasil: nativas e exóticas cultivadas. Nova Odessa, SP: Instituto Plantarum, 2002.

LORENZI, H. Árvores brasileiras: manual de identificação e cultivo de plantas arbóreas do Brasil, vol. 1, 5. ed. Nova Odessa, SP: Instituto Plantarum, 2008.

MARTINS. E.R. et al. Plantas medicinais. Viçosa: UFV, 2000.

MATSUSHITA, M.S. Espécies da sociobiodiversidade vegetal de um fragmento do bioma Floresta Ombrófila Mista e ajuste do modelo matemático para estimativa de fitomassa foliar de guaçatonga (Casearia decandra Jacq.). 2010. 140p. Tese (Doutorado - Área de Concentração em Economia e Política Florestal) - Setor de Ciências Agrárias, Universidade Federal do Paraná. Curitiba,

MENDES, J.T.G. Comercialização Agrícola. Curitiba.
Ed. Universitária. 1998.

MENDES, J.T.G. Economia: fundamentos e aplicações. São Paulo: Prentice Hall, 2004.

MING, L.C. (Coordenador). Mata Atlântica. In: Estratégias para conservação e manejo de recursos genéticos de plantas medicinais e aromáticas: resultados da $1^{\text {a }}$ reunião técnica. Brasília: Embrapa recursos genéticos e biotecnologia / Instituto do meio ambiente e dos recursos naturais renováveis (Ibama) / Conselho Nacional de Desenvolvimento Científico e Tecnológico (CNPq), 2002, p. 61-78.

MOTTA, R.S. Manual para valoração econômica de recursos ambientais. Brasília: Ministério do Meio Ambiente, dos Recursos Hídricos e da Amazônia Legal, 1998. 218p.

OLIVEIRA, F. et al. Morfodiagnose das folhas e das partes reprodutivas de Mikania laevigata Schultz Bip ex Baker. Rev. Bras. Farmacog., n. 1,v. 1, p. 20-34, jan/jun, 1986.

OLIVEIRA, F. et al. Morfologia externa das partes aéreas e anatomia foliar das espécies brasileiras de Mikania secção Globosae Robinson - visão farmacognóstica. LECTA - USF, Bragança Paulista, n. 12, v. 1, p. 23-65, 1994.

RAMOS, A.J.K. (coordenadora). Plantas com potencial medicinal na floresta Nacional de Canela e comunidades do entorno, Canela, Rio Grande do Sul. Porto Alegre: Emater/RS-ASCAR, 2008.

TESKE, M.; TRENTINI, A.M.M. Herbarium: Compêndio de fitoterapia. Curitiba, PR: Herbarium Laboratório Botânico, 1994.

VELLOSO, C.C.; PEGLOW, K. Plantas medicinais. Porto Alegre: Emater/RS-ASCAR, 2003.

VIEIRA, R.F. et al. Estratégias para conservação e manejo de recursos genéticos de plantas medicinais e aromáticas: resultados da $1^{a}$ reunião técnica. Brasília: Embrapa recursos genéticos e biotecnologia / Instituto do meio ambiente e dos recursos naturais renováveis (Ibama) / Conselho Nacional de Desenvolvimento Científico e Tecnológico (CNPq), 2002. 